\title{
An Analysis of the Farmers' Willing to Participate in the Land Ticket Trade Based on the Logistic Model
}

\author{
Xian-Qiang WU ${ }^{1, a}$, Si-Yi PEI ${ }^{2, b,{ }^{*}}$ Ruo-Shan LIU ${ }^{3, c,{ }^{*}}$ \\ ${ }^{1}$ Institute of Economics, Sichuan University, Chengdu, Sichuan, China \\ ${ }^{2}$ Research Institute of Sociology, Sichuan Academic of Social Sciences, Chengdu, Sichuan, China \\ ${ }^{3}$ School of Finance, Southwestern University of Finance and Economics, Chengdu, Sichuan, China \\ a342722928@qq.com, bxiaoqiang1121@126.com
}

Keywords: Chongqing, Land ticket trade, Willing.

\begin{abstract}
Among the land ticket trade system, the farmers need mostly to be protected, the operation of the system must fully respect their willing. In this paper, by constructing logistic model of farmers' willing to participate in the ticket trade, to analyze the factors of influencing farmers' willing. I made a conclusion that the farmers' education level and their trust and intention to the main body of the participation were positively correlated. While the stability their income and understanding of the policy had a negative correlation with their participation intention. Other factors did not show significant effect on the farmers' willing to participate.
\end{abstract}

\section{Introduction}

Since 2008, Chongqing implemented the land ticket system, as of the year of 2014,Dec. 31, Chongqing tickets have been sold 152000 mu reaching the value of 30.64 billion yuan. As one of the main bodies of the whole operation ticket system, farmers' voice is very small or even lack of the voice in the actual operation. This study through investigating the typical regional farmers' willing to participate, analyzing the influencing factors of the farmers' participation, thus providing and promoting further improvement beneficial decision basis and study samples of the ticket system.

\section{The Hypothesis of the Influencing Factors}

There are so many factors of the farmers' participation in land ticket deal, this study will divide the main factors of it into five parts, namely the farmers' personal characteristics (Age, Education level), family characteristics (Major income, Income level, Income stability, Number of Homestead, Other houses, Property status), perception (Policy, Compensation standards, Standard satisfaction), social security (Medical insurance, Social insurance) and farmers' credibility to the collective and the government (Trust of village collective, Trust in local government).

\section{Data Sources and Descriptive Analysis}

The data of this study is from the survey of the Cucumber mountain village of Yongchuan district in Chongqing in January 2015 which belonged to Yongchuan district south street neighborhood offices and was consisted by the original five natural villages. The land area of the village is 20.08 square kilometers and population of it is 6469, the floating population is 5710 with 1956 households and 38 villager groups. Which was the early village to carry out land ticket trade and had strong representation in Chongqing. Questionnaire is the main way of investigation and 280 peasant households took part in this investigation. This investigation got effective questionnaire 271 pieces, the effective rate was $96.7 \%$.

In this survey, the age of object of the survey is from 19 to 77 and young people are the majority. 107 people under the age of 30, is accounted for 39.48\%, 40-50, 94 people, accounted for 34.69\%; As to the men whose age is over 60 or between 30 to 40 are accounted for $1.85 \%$ and $9.59 \%$, respectively. 
This is mainly about the way we did the research, the older of a man the lower cultural level is, so the tendency of filling in the questionnaire is low. At the same time, the number of the people aged between 20 to 40 is low, most of this part of the main labor force have been migrant workers. Just the level of investigators shows that the cultural level is low, the data of the education level below junior high school is accounted for $48.34 \%$. Specific data of the individual farmers' survey analysis is as well as shown in table 1.

Table 1 The basic information of farmers

\begin{tabular}{|l|l|l|l|l|}
\hline Variables & options & Statistics & Percentage(\%) & \\
\hline Age $(\mathrm{X} 1)$ & $>60$ & 5 & 1.85 \\
\hline & $>50$ and $\leq 60$ & 39 & 14.39 & \\
\hline & $>40$ and $\leq 50$ & 94 & 34.69 & \\
\hline & $>30$ and $\leq 40$ & 26 & 9.59 & \\
\hline & $<30$ & 107 & 39.48 & \\
\hline Education $(\mathrm{X} 2)$ & $>$ senior middle school & 73 & 26.94 & \\
\hline & senior middle school & 67 & 24.72 & \\
\hline & Junior middle school & 34 & 12.55 & \\
\hline & Primary school & 90 & 33.21 & 2.58 \\
\hline & $<$ Primary school & 7 & & \\
\hline
\end{tabular}

Table 2 shows the situation of farmers' households. Family income is relatively objective according to the survey, the main source of the income is non-the agricultural , there are 209 households, accounted for $77.12 \%$; But stability of the income is poorer, $75.65 \%$ of farmers believe their income is not stable; As homestead is located in the count, 229 have only one piece of land for building house, There are more than 165 sample objects have domicile; Only 34 families said homestead didn’t obtain legitimate property rights, the specific data show in table 2.

Table 2 Peasant household information

\begin{tabular}{|l|l|l|l|l|}
\hline Variables & options & Statistics & Percentage(\%) \\
\hline Major income(X3) & Agriculture & 62 & 22.88 & \\
\hline & Non agriculture & 209 & 77.12 & \\
\hline Income level(X4) & $>50$ thousand & 55 & 20.29 & \\
\hline & $>40$ and $\leq 50$ thousand & 72 & 26.57 & \\
\hline & $>30$ and $\leq 40$ thousand & 69 & 25.46 & \\
\hline & $>20$ and $\leq 30$ thousand & 39 & 14.39 & \\
\hline & $\leq 20$ thousand & 36 & 13.28 & \\
\hline Income stability(X5) & YES & 66 & 24.35 & \\
\hline & NO & 205 & 75.65 & \\
\hline Number of Homestead(X6) & $>2$ & 14 & 5.17 & \\
\hline & 2 & 28 & 10.33 & \\
\hline & 1 & 229 & 84.5 & 39.11 \\
\hline Other houses(X7) & YES & 106 & 60.89 & \\
\hline & NO & 165 & 237 & 87.45 \\
\hline Property status(X8) & YES & 34 & 12.55 & \\
\hline & NO & & & \\
\hline
\end{tabular}

Table 3 shows the farmers' perception to the policy, main option is the understanding of the policy, understanding of the compensation standard and compensation standard of satisfaction. The farmer' understanding, hearing, and not knowing the proportion of the original ticket system are 22.88\%, $65.68 \%$ and $22.88 \%$ respectively; 67 farmers' said they understood the compensation standard. For 
those who didn't understand the proportion of compensation standard is as high as $75.28 \%$; 232 said they were not satisfied with the compensation standard, only 39 expressed satisfaction.

Table 3 Farmers' understand of policy

\begin{tabular}{|l|l|l|l|}
\hline Variables & Options & Statistics & Percentage(\%) \\
\hline Policy(X9) & Understand & 62 & 22.88 \\
\hline & Know a little & 178 & 65.68 \\
\hline & Not heard & 31 & 11.44 \\
\hline Compensation standards(X10) & Understand & 67 & 24.72 \\
\hline & Do not understand & 204 & 75.28 \\
\hline Standard satisfaction(X11) & Satisfied & 39 & 14.39 \\
\hline & Dissatisfied & 232 & 85.61 \\
\hline
\end{tabular}

Table 4 is the farmers' social security situation table which reflected the situation of the farmers' social security. It can be seen that medical insurance is relatively good at the rate of $90.04 \%$; the rate of the endowment insurance is $48.71 \%$, which did not meet the half.

Table 4 Farmers insurance situation

\begin{tabular}{|l|l|l|l|l|}
\hline Variables & Options & Statistics & Percentage(\%) & \\
\hline Medical insurance(X12) & YES & 244 & 90.04 & \\
\hline & NO & 27 & 9.96 & \\
\hline Social insurance(X13) & YES & 132 & 48.71 & \\
\hline & NO & 139 & 51.29 & \\
\hline
\end{tabular}

Table 5 reflected the village collective farmers' trust of the local government, in fact, it reflected the performance of local government and village collective credibility. Results showed that farmer's trust in the collective and government proportion are $67.16 \%$ and $63.10 \%$ respectively, it can be seen that the proportion is not high.

Table 5 Farmers' trust in village collective and local government

\begin{tabular}{|l|l|l|l|l|}
\hline Variables & Options & Statistics & Percentage(\%) & \\
\hline Trust of village collective(X14) & YSE & 182 & 67.16 & \\
\hline & NO & 89 & 32.84 & \\
\hline Trust in local government(X15) & YSE & 171 & 63.1 & \\
\hline & NO & 100 & 36.9 & \\
\hline
\end{tabular}

\section{Model Selection and Variable}

In general, we used binary model of Logistic regression analysis to analyze the willingness, so in this article the wishes of farmers' participation in land ticket trade can be set as the dependent variable y, the dependent variable is $0 \sim 1$ type, farmers willing to participate in trade can be defined as "y $=1$ ", not willing to is defined as " $y=0 "$. By using the binary Logistic model, the dependent variable must range the limit values between $(0,1)$. So, simple willing function can be expressed as: will $=\mathrm{F}$ (personal characteristics, family characteristics, social security situation, perception, the related subject of trust) + random perturbation terms.

Set $\chi_{1}, \chi_{2}, \ldots, \chi_{k}, \chi_{k}$ are independent variables, related to the $\mathrm{y}$, there are $\mathrm{N}$ sets of observational data, namely: $\left(\chi_{\mathrm{i} 2}, \chi_{\mathrm{i} 2}, \ldots, \chi_{\mathrm{ik}} ; \mathrm{y}_{\mathrm{i}}\right) ;(\mathrm{i}=1,2,3, \ldots, \mathrm{n})$. Among them, $\mathrm{y}_{\mathrm{i}}$ is the value of 0 or 1 dependent variables. The relationship between $\mathrm{y}_{\mathrm{i}}$ with $\chi_{\mathrm{i} 1}, \chi_{\mathrm{i} 2}, \ldots, \chi_{\mathrm{ik}}$ is: 


$$
E\left(\mathrm{y}_{\mathrm{i}}\right)=\mathrm{p}_{\mathrm{i}}=\beta_{0}+\beta_{1} \chi_{\mathrm{i} 1}+\beta_{2} \chi_{\mathrm{i} 2}+\ldots+\beta_{k} \chi_{i k}
$$

The Logistic regression function:

$$
\mathrm{f}\left(\mathrm{p}_{\mathrm{i}}\right)=\frac{\mathrm{e}^{\mathrm{p}_{\mathrm{i}}}}{1+\mathrm{e}^{\mathrm{p}_{\mathrm{i}}}}=\frac{\mathrm{e}^{\left(\beta_{0}+\beta_{1} \chi_{\mathrm{i} 1}+\beta_{2} \chi_{\mathrm{i} 2}+\ldots+\beta_{\mathrm{k}} \chi_{\mathrm{ik}}\right)}}{1+\mathrm{e}^{\left(\beta_{0}+\beta_{1} \chi_{\mathrm{i} 1}+\beta_{2} \chi_{\mathrm{i} 2}+\ldots+\beta_{\mathrm{k}} \chi_{\mathrm{ik}}\right)}}
$$

We assign the various variants in the same direction and calculate their average and standard deviation.

\section{Model to Estimate the Result and Analysis}

\section{Estimate and Test Results}

According to the data of the survey, by using the Logistic regression analysis to analyze the 271 samples of families through eviews6.0 statistical software for cross section data. In dealing with the analysis process, by using the Forward Conditional analysis method, gradually, to increase the influencing factors. From the results of running the model, model of $\mathrm{R}$ values of 0.86 , the fitting degree is higher, LR test values of $248.96(p=0.00)$, the overall inspection results ideal, estimated result is stable, the result of model calculation is as table 6:

Table 6 Logistic model regression analysis of factors affecting farmers' willingness to participate in land transaction

\begin{tabular}{|l|l|l|l|l|}
\hline & Coefficient & Std. Error & z-Statistic & Prob. \\
\hline X2 & 2.644246 & 0.804852 & 3.285379 & 0.001 \\
\hline X5 & -5.786385 & 1.857107 & -3.115806 & 0.0018 \\
\hline X9 & -1.686282 & 0.819402 & -2.057943 & 0.0396 \\
\hline X14 & 8.568897 & 2.021351 & 4.239194 & 0 \\
\hline X15 & 10.03759 & 2.13066 & 4.711022 & 0 \\
\hline C & -9.505812 & 3.458835 & -2.74827 & 0.006 \\
\hline McFadden R-squared & 0.861351 & Mean dependent var & 0.774908 \\
\hline S.D. dependent var & 0.418416 & S.E. of regression & 0.129347 \\
\hline Akaike info criterion & 0.192157 & Sum squared resid & 4.433655 \\
\hline Schwarz criterion & 0.271909 & Log likelihood & -20.03726 \\
\hline Hannan-Quinn criter. & 0.224178 & Restr. log likelihood & -144.5183 \\
\hline LR statistic & 248.9621 & Avg. log likelihood & -0.073938 \\
\hline Prob(LR statistic) & 0 & \multicolumn{3}{|l}{} \\
\hline
\end{tabular}

\section{Estimate the Result Analysis}

It is can be seen from table 6model regression analysis results, different factors that affect the willing of farmers ' participation in land ticket trade are not the same. By running the model, the significant factors mainly are:

\section{The Farmers' Personal Characteristics}

First, the education level of farmers' personal characteristics on their participation will have a significant impact, both of them are positively correlated. Because of the higher level of culture, their vision is more open, the ability to accept new things and new knowledge is faster, And the better understanding to the national new policy, the more ability to analyze and solve problems from a long-term plan . In addition, as for the farmers with relatively high cultural level who study and work out all the year round, seldom come back to the countryside, in fact the homestead for them meant only the taste of home, by participating in land reclamation and land ticket trade, they can not only get 
a revenue, but also take root in the city as early as possible. Second, as for the age, the model analysis results did not show a significant impact on the farmers. Reason was that maybe in our country's rural areas, farmers' culture level and age had a significant negative relationship, the older you get, the less likely to accept new things. In addition to the grandparents' plot, they may not be willing to participate in; , on the other hand, many farmers' children have moved to the city, many old men are living in the cities with their children, so they were willing to participate in, and in our research, the research object of age distribution is not reasonable (the old man' willing to participate in the research is low), so the test showed that there is no significant difference among age for farmers to participate.

\section{Farmers Family Characteristics}

In analysis of farmers' family characteristics, the model results showed that the stability of farmers' income had obvious effects to their participation, the two had negative relationship This contradicted the policy that farmers' reclamation must have a stable income as the prerequisite conditions in Chongqing. Cucumber mountain village outside workers were not at home all the year round, the house income was lack of stability, they would like to take root but were lack of funds, therefore they displayed higher participation willing, of course, this was on the one hand, the real reason was that most of them do not have a high level of culture, knowing about policy was not enough, besides, they didn't know the homestead and can't apply the rules of after sale. Whether the income was from business or farming, or other professional, had no significant influence on the behavior, that is, different professions, will not participate differently for professional reasons. In terms of income levels, the results were not significant, may find the person with higher income levels of the current compensation of 120000 yuan/mu after reclamation in Chongqing, and most people's land area is not large also, to tens of thousands of yuan, for those people with high income, it doesn't matter a lot, they might as well keep the old house, when they were back they can still live in, and in the context of national policy, the homestead had appreciation potential. For those people with lower income who was unable to make their homes in the city, maybe they wanted to get the compensation, so their participation intention is higher, but the model is running with high and low income people together in calculation, the negative relationship may lead to the income factors not significant. Another homestead was located in number, residence, and other property rights situation did not show significant effect.

\section{Farmers' Awareness of Policy}

In this section, we chose the understanding of the policy, the understanding of the compensation standard and compensation standard of the satisfaction as the three options. The results showed that the degree of understanding of the policy had a significant effect, and had the opposite relationship. While the standard of compensation and compensation standard satisfaction options did not show significant effect. In theory, with better understanding of a policy, if the policy is more conducive to the interests of the participants, the farmers' participation should be higher, but the model showed a negative relationship. We can analyze that, as they appeared such result, it is likely that the process of developing and implementing the policy was lack of protection of farmers' rights and interests, the more farmers understood the policy, the more knowing themselves in the whole process of participation to the rights and interests of the losses sustained. Such as farmers' participation was not enough in the policy making, policy did not fully embody the farmers' willing, no displaying of farmland value compensation standard, farmers' lack of power in the execution, and the lack of transparency and fairness.

\section{The Implementation of Farmers’ Social Security}

In this section, medical insurance and social insurance did not show a significance for farmers' participation, on the one hand, the current rural cooperation medical insurance and insurance rate was very high, almost everyone had; On the other hand, in terms of old house (land), farmland which is not in the countryside, almost won't generate economic value and didn't have social security function like farmland, so it didn’t have obvious relationship to farmers' willing to participate. 


\section{Farmers’ Trust on the Government and Collective}

As the running of the model showed, according to the results of the farmer's trust in the participation main body and farmers' willing to participate were positively related and the effect was remarkable. The more trust in the village collective and local government, the stronger willing they showed in participating the land trade. This was mainly because with China's political reform and democratization, especially a lot of migrant farmers in the eastern coastal areas enjoyed a high political civilization, to be respected and had a right to voice. The government credibility, tended to be more important than the compensation amount. Therefore, the more trust to the village collective farmers and local governments the higher participation intention they showed.

\section{Conclusion}

The result of the study showed that the farmers' education level and the trust to main body's participation and intention were positively correlated. The higher level of education the farmers had, the higher trust to the government and collective. So the willing to participate was more positive; stability of the Income and understanding of the policy had a negative correlation to the participation. For the farmers, the more stable income, the better understanding of the policy , the lower participation intention they would have; Other factors did not show significant effect to farmers' willing to participate.

\section{References}

[1]Douglas C Macmillan. An Economic Case for Land Reform [J]. Land Use Policy, 2000, 17(1): 49-57.

[2]Anka Lisee,Miran Ferlan, Franc Lobnik, et al.Modelling the rural land transaction procedure [J]. Land Use Policy, 2008(25):286-297.

[3]Grigorios Livanis, Charles B. Moss et al. Urban Sprawl and Farmland Prices [J]. American Journal of Agricultural Economics, 2006, 88 (4): 915-929.

[4]Jirui Yang, Rui Wang, Yongkun Ma. Exploration on the innovation of "land ticket" trade in Chongqing[J]. Chinese Rural Economy, 2010(11):4-9.(In Chinese) 